\title{
Replenishment of Magma Chambers by Light Inputs
}

\author{
Herbert E. Huppert, ${ }^{1}$ R. Stephen J. Sparks, ${ }^{2}$ John A. Whitehead, ${ }^{3}$ and Mark A. Hallworth ${ }^{1}$
}

\begin{abstract}
Magma chambers, particularly those of basaltic composition, are often replenished by an influx of magma whose density is less than that of the resident magma. This paper describes the fundamental fluid mechanics involved in the replenishment by light inputs. If $\rho$ denotes the uniform density of the resident magma and $\rho-\Delta \rho$ that of the input, the situation is described by the reduced gravity $g^{\prime}=g \Delta \rho / \rho$, the volume flux $Q$, and the viscosities of the resident and input magmas $v_{e}$ and $v_{t}$, respectively. The (nondimensional) Reynolds numbers, $\operatorname{Re}_{e}=\left(g^{\prime} Q^{3}\right)^{1 / 5} / v_{e}$ and $\operatorname{Re} e_{1}=\left(g^{\prime} Q^{3}\right)^{1 / 5} / v_{i}$ and chamber geometry then completely specify the system. For sufficiently low values of the two Reynolds numbers (each less than approximately 10 ), the input rises as a laminar conduit. For larger values of the Reynolds numbers, the conduit may break down and exhibit either a varicose or a meander instability and entrain some resident magma. At still larger Reynolds numbers, the flow will become quite unsteady and finally turbulent. The values of the Reynolds numbers at which these transitions occur have been documented by a series of experiments with water, glycerine, and corn syrup. If the input rises as a turbulent plume, significant entrainment of the resident magma can take place. The final spatial distribution of the mixed magma depends on the geometry of the chamber. If the chamber is much wider than it is high, the mixed magma forms a compositionally stratified region between the roof and a sharp front above uncontaminated magma. In the other geometrical extreme, the input magma is mixed with almost all of the resident magma. If the density of the resident magma is already stratified, the input plume may penetrate only part way into the chamber, even though its initial density is less than that of the lowest density resident magma. The plume will then intrude horizontally and form a hybrid layer at an intermediate depth. This provides a mechanism for preventing even primitive basaltic magmas of minimum density from erupting at the surface. By conducting an experiment using aqueous solutions, we show that entrainment can lead to crystallization of the magma in the input plume by making it locally supersaturated. All these effects are discussed and illustrated by photographs of laboratory experiments.
\end{abstract}

\section{INTRODUCTION}

The last few years have seen considerable progress in the understanding of the fluid dynamical evolution of replenished magma chambers. All but two of the investigations (as reviewed by Huppert and Sparks [1984] and Sparks et al. [1984]) considered the chamber to be replenished by magma whose density exceeded that of the resident magma. The new magma thus ponded at the base of the chamber. The only investigations that considered the incoming magma to be less dense than the resident magma were those by Sparks et al. [1980] and by Campbell et al. [1983]. The former pointed to the possibility that the new magma would rise as a turbulent plume through the resident magma and entrain part of it, while the latter used this concept to provide an explanation for the formation of platinium-sulphide ore deposits in the Bushveld and Stillwater complexes. The aim of this paper is to explore the fundamental fluid mechanics of this situation more completely. We investigate the influence of the chamber geometry, stratification within the chamber, and crystallization, on the fluid dynamical behavior of relatively light inputs. We also explore the form of motion for Reynolds numbers in the transitional range between laminar and turbulent values. In particular, we describe the fluid mechanical effects and flow regimes due to the input and resident magmas having different viscosities.

If the new magma is ejected from a relatively small vent (very much less in diameter than the height of the chamber), it can be considered to issue from a point source just below the

\footnotetext{
'Department of Applied Mathematics and Theoretical Physics, University of Cambridge, England.

${ }^{2}$ Department of Earth Sciences, University of Cambridge, England.

${ }^{3}$ Woods Hole Oceanographic Institution, Woods Hole, Massachusetts.
}

Copyright 1986 by the American Geophysical Union.

Paper number 4B5408.

0148-0227/86/004B-5408\$05.00 vent opening. Suppose that the density of the resident magma is $\rho$ and that of the input magma is $\rho-\Delta \rho$ (where $\Delta \rho$ is positive), then the fluid system is described by four parameters: the volume flow rate, $Q$; the reduced gravity, $g^{\prime}=g \Delta \rho / \rho$, where $g$ is the acceleration due to gravity; the kinematic viscosity of the input magma, $v_{i}$; and that of the existing resident magma, $v_{e}$. From these four parameters it is possible to form only two independent, dimensionless parameters. For convenience, we choose two which we associate with the internal and external Reynolds numbers

$$
\begin{aligned}
& R e_{i}=\left(g^{\prime} Q^{3} / v_{i}^{5}\right)^{1 / 5} \\
& R e_{e}=\left(g^{\prime} Q^{3} / v_{e}^{5}\right)^{1 / 5}
\end{aligned}
$$

(Some of the reasoning behind this choice is given in the appendix.) As will be discussed below, the geologically relevant range is given by

$$
\begin{aligned}
& 0<R e_{i}<10^{4} \\
& 0<R e_{e}<10^{4}
\end{aligned}
$$

In this paper we map out the fundamental fluid mechanical phenomena as a function of these two Reynolds numbers and the chamber geometry. The motions when both $R \boldsymbol{e}_{i}$ and $R \boldsymbol{e}_{e}$ are sufficiently large that viscous effects can be neglected are the subject of the next section. We first briefly describe the motion when the new magma rises as a turbulent plume unaffected by the walls of the chamber. We then discuss phenomena due to the containing walls and, in particular, point out the different effects in wide, short chambers and narrow, tall ones. The influences of vertical stratification in the resident magma are then discussed, and the differences due to the stratification varying continuously or in layers is brought out. The section ends with an investigation of effects due to the formation of crystals in the rising plume; these crystals result from supersaturation induced by mixing with the resident magma.

The forms of motion and the amount of mixing for smaller Reynolds numbers, when viscous effects are important, are the 


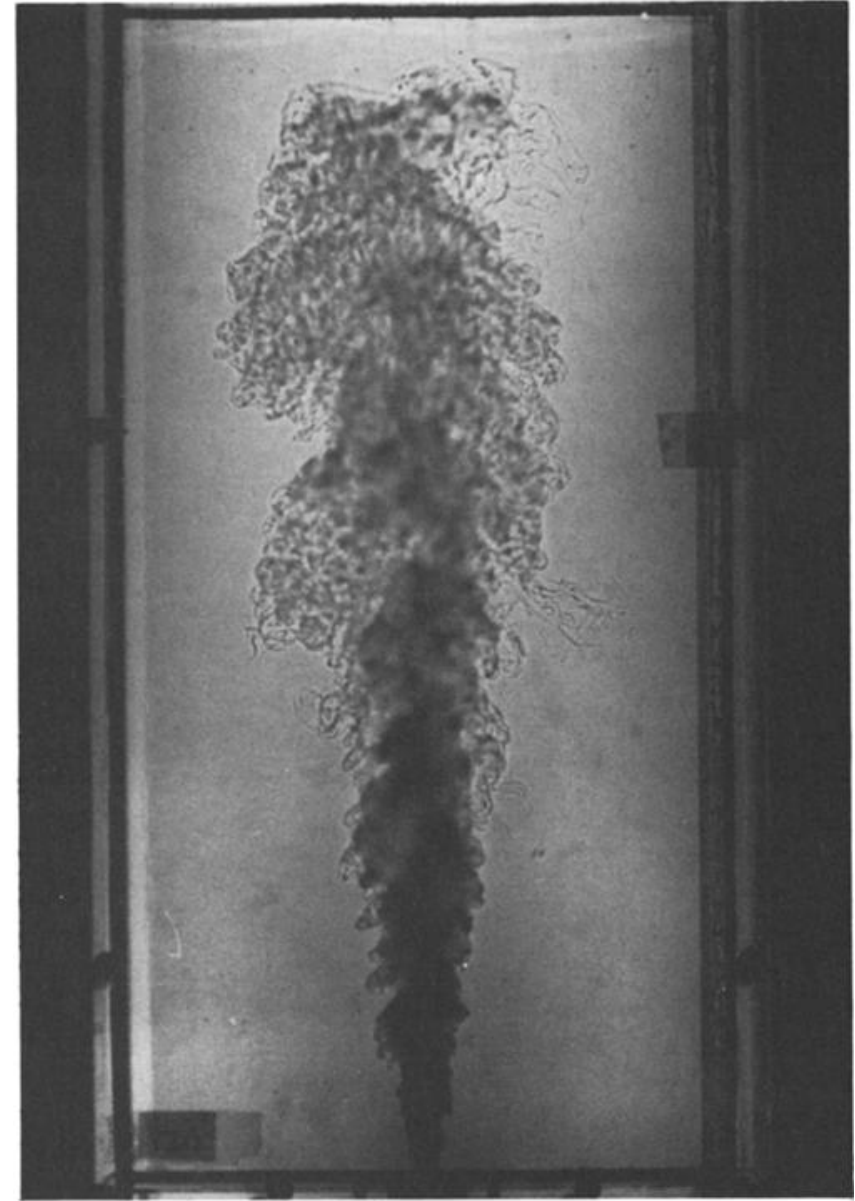

Fig. 1. A photograph of a laboratory plume of dyed salt water rising into fresh water. $Q=8.9 \times 10^{-6} \mathrm{~m}^{3} \mathrm{~s}^{-1}, g^{\prime}=0.77 \mathrm{~m} \mathrm{~s}^{-2}, v_{i} \approx$ $v_{e} \approx 10^{-6} \mathrm{~m}^{2} \mathrm{~s}^{-1}, R e_{t} \approx R e_{e} \approx 900$. Note the convoluted envelope of the plume, indicating the intermittent entrainment by the turbulent eddies in the plume.

subject of section 3. Our conclusions, with some geological interpretations, make up the final section.

\section{LARGe ReYNolds Numbers}

\subsection{Fundamental Concepts}

If both Reynolds numbers are sufficiently large, the input magma will rise as a turbulent plume and entrain the surrounding magma. The entrainment occurs by turbulent eddies

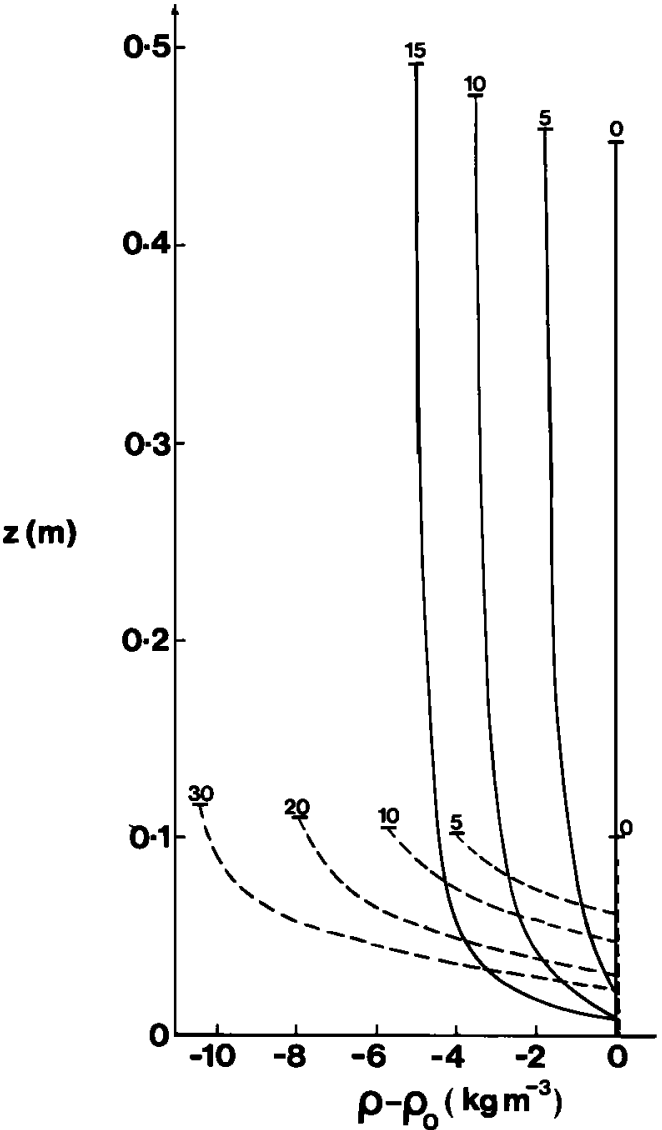

Fig. 3. The resultant density profiles for plumes issuing into chambers of small (dashed curves) and large (solid curves) aspect ratios. The density is plotted as $\rho-\rho_{0}$ with $\rho_{0}=1046 \mathrm{~kg} \mathrm{~m}^{-3}$. The profiles are shown initially and at subsequent times, as marked in minutes above each curve. The short horizontal bar at the top of each curve represents the top of the fluid layer. Note the relatively large stratification built up in the small aspect ratio case, in contrast to the large aspect ratio situation. In both cases, $Q=2.3 \times 10^{-6} \mathrm{~m}^{3} \mathrm{~s}^{-1}$, $g^{\prime}=0.45 \mathrm{~m} \mathrm{~s}^{-2}, v_{i} \approx v_{e} \approx 10^{-6} \mathrm{~m}^{2} \mathrm{~s}^{-1}, R e_{i} \approx R e_{e} \approx 350$. The initial layer for the small aspect ratio case was $0.58 \mathrm{~m} \times 0.43 \mathrm{~m} \times 0.10 \mathrm{~m}$ deep, while that for the large aspect ratio case was $0.20 \mathrm{~m} \times 0.20$ $\mathrm{m} \times 0.40 \mathrm{~m}$ deep.

in the plume engulfing the surrounding magma. The plume thus expands, and the density contrast decreases as it rises. The envelope of the plume, on average, takes the form of a cone which makes an angle of order $10^{\circ}$ to the vertical. A

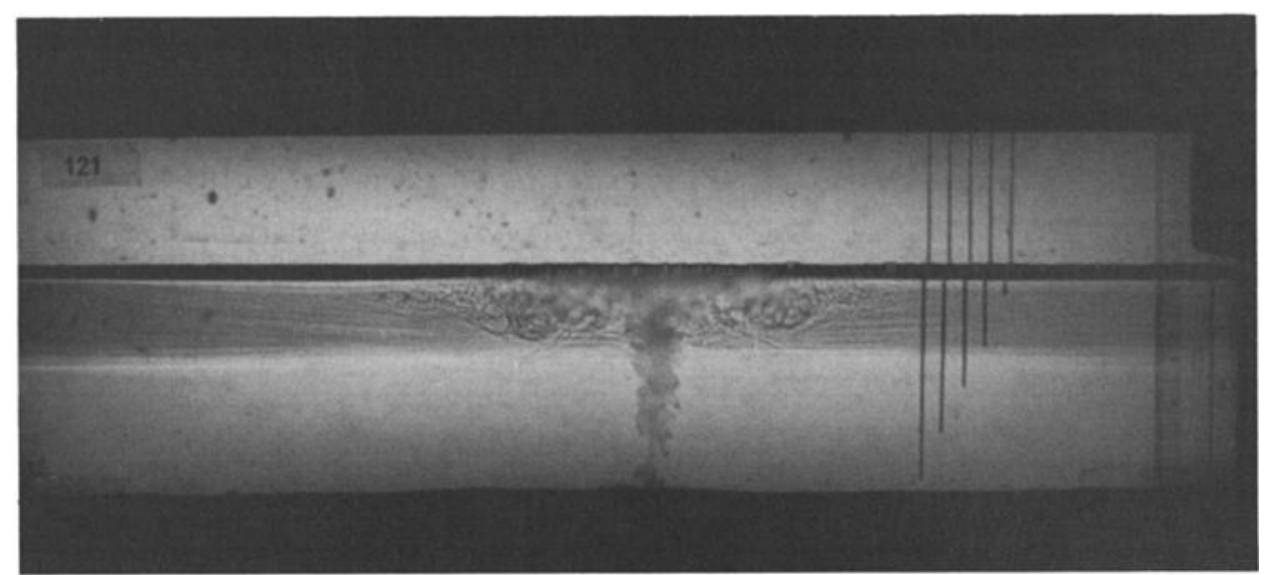

Fig. 2. A photograph of an experiment in which a plume of fresh water has risen through relatively heavier salty water in a chamber of low aspect ratio to form a stratified region above the descending sharp front. $Q=2.1 \times 10^{6} \mathrm{~m}^{3} \mathrm{~s}^{-1}$ $g^{\prime}=0.4 \mathrm{~m} \mathrm{~s}^{-2}, v_{i} \approx v_{e} \approx 10^{-6} \mathrm{~m}^{2} \mathrm{~s}^{-1}, R e_{i} \approx R e_{e} \approx 400$. The resident fluid layer was $0.50 \mathrm{~m} \times 0.20 \mathrm{~m} \times 0.10 \mathrm{~m}$ deep and the photograph was taken 5 min after the initiation of the plume. 


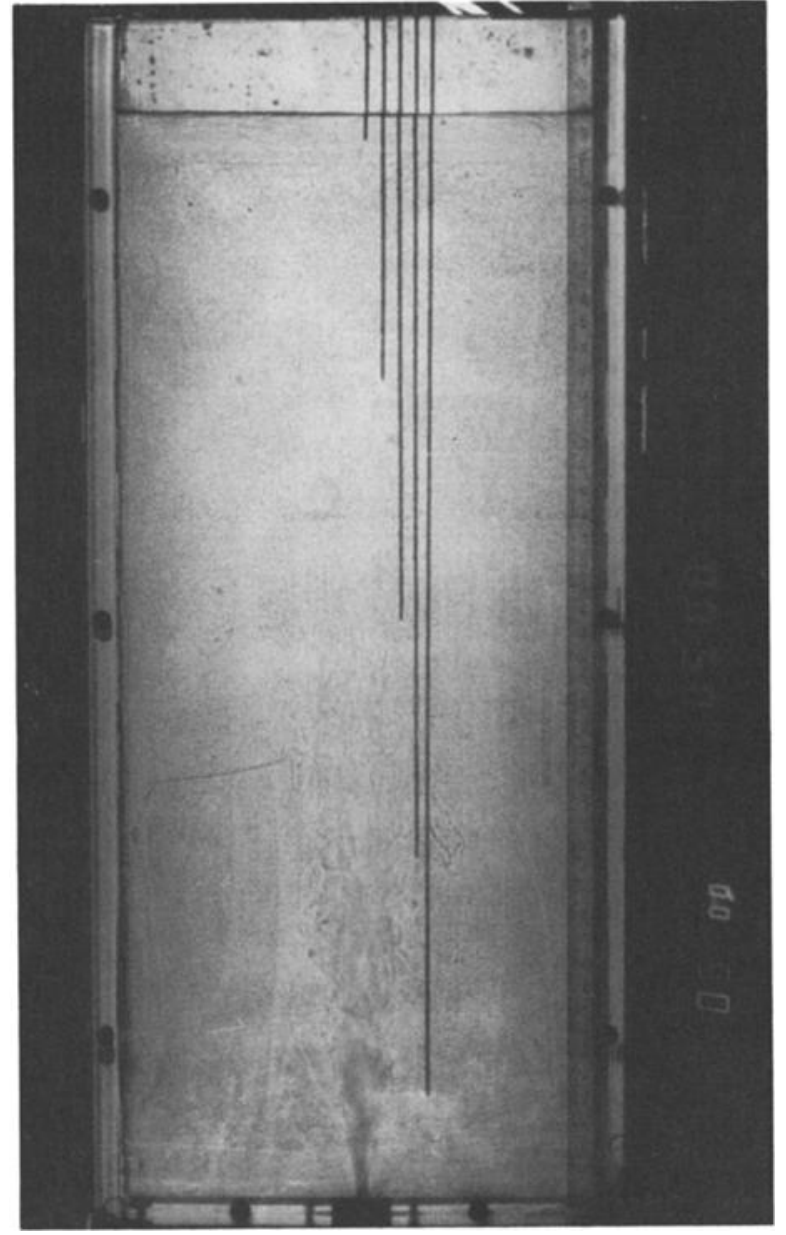

Fig. 4. A photograph of an experiment in which a plume of fresh water has risen through relatively heavier salty water in a chamber of large aspect ratio to form a relatively uniformly stratified region behind a diffuse front. $Q=2.1 \times 10^{-6} \mathrm{~m}^{3} \mathrm{~s}^{-1}, g^{\prime}=0.45 \mathrm{~m} \mathrm{~s}^{-2}, v_{t} \approx$ $v_{e} \approx 10^{-6} \mathrm{~m}^{2} \mathrm{~s}^{-1}, R e_{i} \approx R e_{e} \approx 400$. The resident fluid layer was 0.20 $\mathrm{m} \times 0.20 \mathrm{~m} \times 0.44 \mathrm{~m}$ deep and the photograph was taken $5 \mathrm{~min}$ after the initiation of the plume. laboratory simulation is shown in Figure 1. For details of the velocity and density distribution within the plume and its rate of rise, the reader is referred to Turner [1979] or Turner and Gustafson [1978]. Because the molecular effects of viscosity and diffusion play no role in this case, two important statements can be made. First, laboratory data can be easily scaled to yield results appropriate to large-scale geological situations, and second, the buoyancy is proportional to the total density difference, whether it be due to temperature, composition, or both.

\subsection{Issuance Into a Chamber of Low Aspect Ratio}

If the chamber is very much wider than it is high, as exemplified by a sill, the new magma takes the form of a turbulent plume, as already described, until it reaches the roof. It then spreads as a mainly laminar layer on top of the resident magma. Subsequent magma in the plume passes through this laminar layer, entrains part of it, and arrives at the roof even lighter. In this way the input magma, contaminated by resident magma, builds up a stratified region of mixed magma at the roof behind a sharp front. A laboratory simulation is presented in Figure 2. A relationship for the rate of descent of the front was first determined by Baines and Turner [1969]. The region behind the front will be stratified, with a gradient which can be evaluated from the results of Worster and Huppert [1983]. An example of the stratification is presented in Figure 3.

\subsection{Issuance Into a Chamber of Large Aspect Ratio}

If the chamber is very much higher than it is wide, well before the plume can rise to the top it will have expanded sufficiently for the containing walls to have a very strong influence. Our laboratory simulations indicate that the input magma is mixed almost uniformly into the resident magma with, at best, a very weak interface close to the vent. Figure 4 presents a photograph of an experiment, and Figure 3 plots the stratification in a way that allows for comparison with the result for a small aspect ratio.

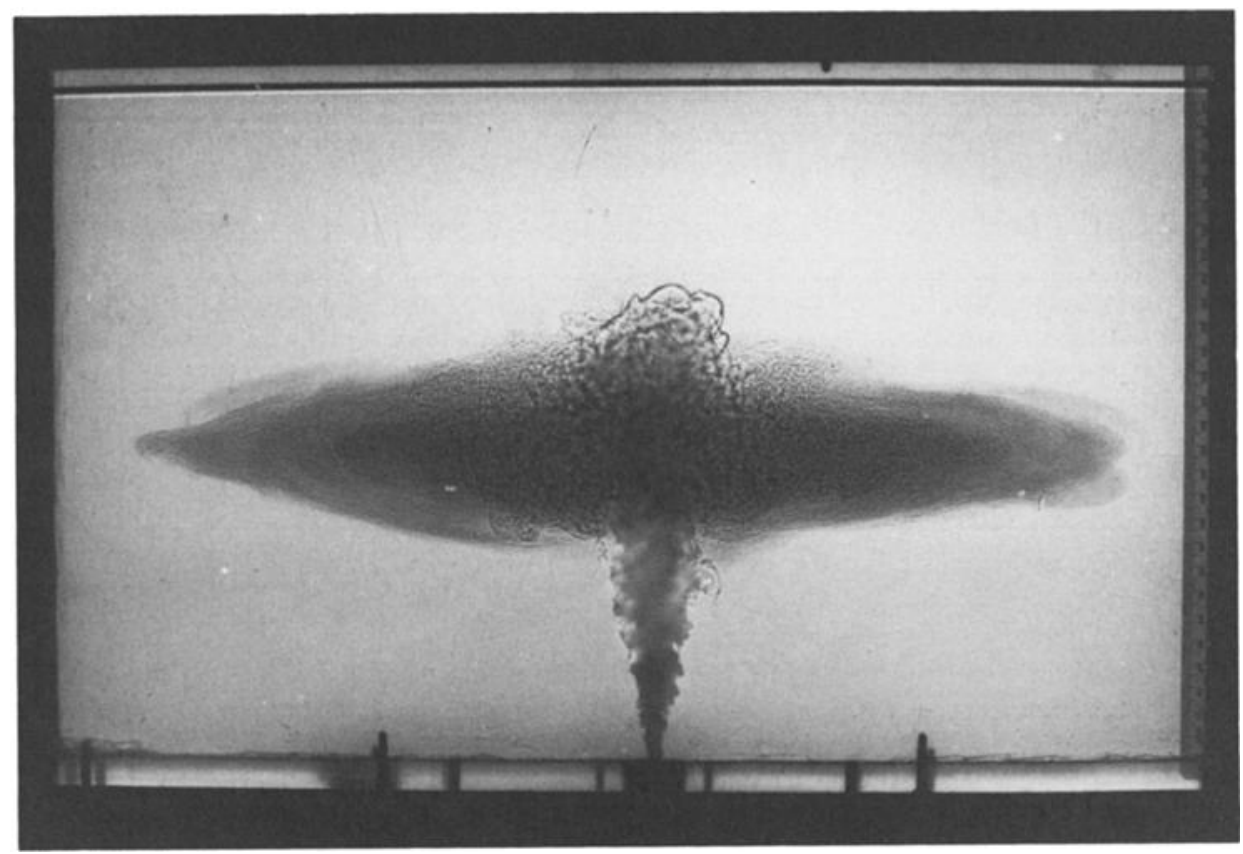

Fig. 5. Photograph of a plume of fresh water rising in a stratified medium and forming an intrusion at an intermediate depth. Note the inertial overshoot in the plume which takes the fluid beyond the level of the intrusion. $Q=4.7 \times 10^{-6} \mathrm{~m}^{3}$ $\mathrm{s}^{-1}, g^{\prime}=0.88 \mathrm{~m} \mathrm{~s}^{-2}, N=1.08 \mathrm{~s}^{-1}, Z=0.079 \mathrm{~m}$. 

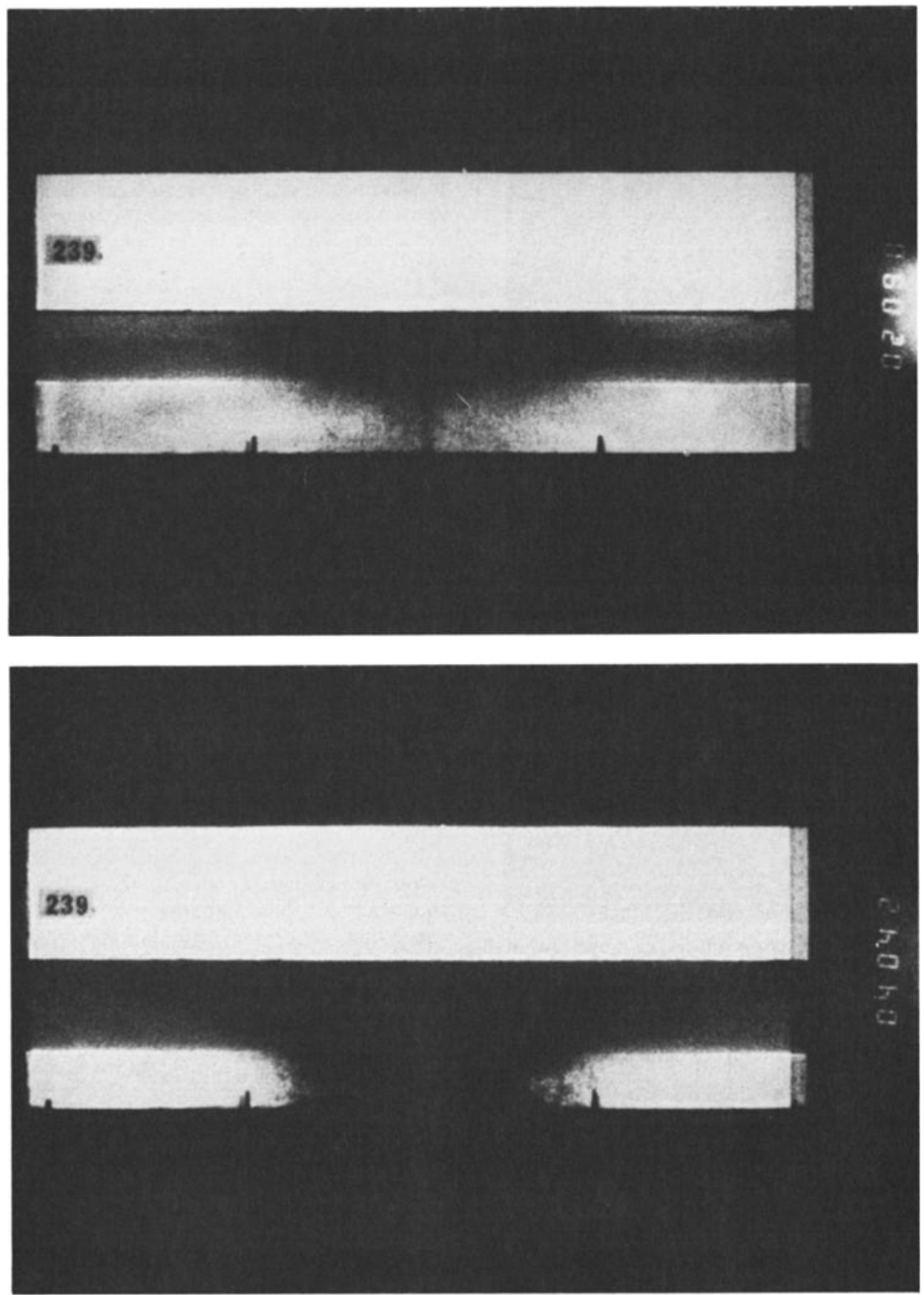

Fig. 6. Two photographs of an experiment in which a hot plume of almost saturated $\mathrm{KNO}_{3}$ rises in a relatively cold layer of $\mathrm{K}_{2} \mathrm{CO}_{3}$. Crystals of $\mathrm{KNO}_{3}$ rain out of the plume due to the reduced solubility of $\mathrm{KNO}_{3}$ in the presence of the entrained $\mathrm{K}_{2} \mathrm{CO}_{3}$. The photographs were taken after (top) $2 \min 9 \mathrm{~s}$ and (bottom) $4 \min 4 \mathrm{~s}$. Other experimental details are described in the text.

\subsection{Effects of Preexisting Stratification}

Prior to the input, the resident magma might be vertically stratified, either continuously or in the form of layers. The major effect of the density of the resident magma decreasing with height is that the plume, which entrains relatively heavy magma from the base of the chamber, may come to a height where its density equals that of the resident magma. Inertia may take it somewhat higher, but it will then sink back and intrude sideways into the magma chamber, as seen in the photograph of the laboratory experiment shown in Figure 5. If the resident magma is continuously stratified, this could occur at any height, dependent only on the input conditions. If the resident magma is stratified in (uniform) layers, the intrusion can only occur at an interface between two layers. Note possibly the most important feature of the intrusion: due to the entrainment of relatively heavy magma into the plume, the density at the level of the intrusion can be significantly greater than the original input density. We quantify this effect and present numerical examples below.

With a stratification for which the vertical density gradient is constant, and denoted by $\phi$, there are two fundamental parameters which describe the fluid system. These are the spe- 
TABLE 1. Density and Kinematic Viscosity of Each of the Fluids Used in This Study

\begin{tabular}{lcc}
\hline \multicolumn{1}{c}{ Fluid } & $\begin{array}{c}\text { Density at } \\
20^{\circ} \mathrm{C}, \mathrm{kg} \mathrm{m}^{-3}\end{array}$ & $\begin{array}{c}\text { Kinematic Viscosity } \\
\text { at } 20^{\circ} \mathrm{C}, \mathrm{m}^{2} \mathrm{~s}^{-1}\end{array}$ \\
\hline Water & 998 & $1.00 \times 10^{-6}$ \\
Glycerine & 1261 & $1.19 \times 10^{-3}$ \\
Corn syrup & 1437 & $1.2 \times 10^{-1}$ \\
\hline
\end{tabular}

cific buoyancy flux

$$
F=g^{\prime} Q
$$

and the buoyancy frequency

$$
N=(g \phi / \bar{\rho})^{1 / 2}
$$

where $\bar{\rho}$ is an appropriate mean density of the resident magma. From $F$ and $N$, only one parameter with the dimensions of length can be formed. It can be written as

$$
l_{F N}=\left(F / N^{3}\right)^{1 / 4}
$$

Experiments [Briggs, 1969] show that in this circumstance the height of the intrusion above the vent $Z$ is given by

$$
Z=1.85 l_{F N}
$$

Note that the plume has virtually no influence above this height.

For numerical illustration, consider a magma of density $2650 \mathrm{~kg} \mathrm{~m}^{-3}$ to be input at $100 \mathrm{~m}^{3} \mathrm{~s}^{-1}$ into the base of a chamber $1 \mathrm{~km}$ high. Let the density of the resident magma decrease at a constant rate from $2700 \mathrm{~kg} \mathrm{~m}^{-3}$ at the base to $2660 \mathrm{~kg} \mathrm{~m}^{-3}$ at the roof. Then $F=18 \mathrm{~m}^{4} \mathrm{~s}^{-3}, N=1.2$ $\times 10^{-2} \mathrm{~s}^{-1}$, and the height of the rise $Z=104 \mathrm{~m}$. Note that the height of rise is a small fraction of the height of the chamber even though the density of the input magma is less than that of the lowest-density resident magma at the roof.

Because the plume can spread horizontally only along an interface of a layered chamber, the height of rise in such a chamber can vary significantly from that for a continuously stratified chamber, even though the density profiles may be

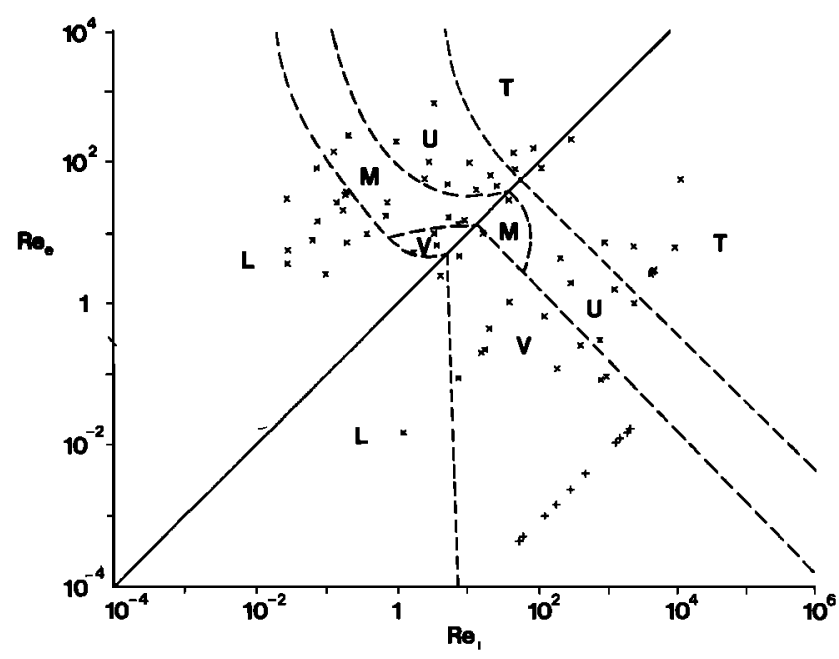

Fig. 7. The Reynolds number regime diagram for the experiments we conducted. The crosses are data obtained using water/glycerine mixtures, and the pluses are data obtained using water and corn syrup. The form of motions are as follows. $L$, laminar; V, varicose instability; $M$, meander instability; $U$, unsteady; and $T$, turbulent. The dashed curves are approximate boundaries for the various regimes. quite similar. Thus, in the above examples, if the chamber consists of two layers of equal depths, with the lower one of uniform density $2700 \mathrm{~kg} \mathrm{~m}^{-3}$, the plume will rise to a level $Z$ of $500 \mathrm{~m}$ as long as the density of the upper layer is less than $2696 \mathrm{~kg} \mathrm{~m}^{-3}$. Otherwise the plume will rise to the roof.

\subsection{Precipitation Within the Plume}

To investigate effects due to the entrained magma supersaturating the input magma, we carried out the following experiment. An aqueous solution of $\mathrm{KNO}_{3}$ at $60^{\circ} \mathrm{C}$ with specific gravity 1.280 was input at a rate of $3 \times 10^{-6} \mathrm{~m}^{3} \mathrm{~s}^{-1}$ to the base of a container which was filled to a depth of $83 \mathrm{~mm}$ with an aqueous solution of $\mathrm{K}_{2} \mathrm{CO}_{3}$ at $5.5^{\circ} \mathrm{C}$ with specific gravity 1.329. The solubility of $\mathrm{KNO}_{3}$ is strongly decreased both by the presence of $\mathrm{K}_{2} \mathrm{CO}_{3}$ [Mellor, 1965; Huppert and Turner, 1981] and by a decrease in temperature [Washburn, 1929]. The entrainment of cold aqueous $\mathrm{K}_{2} \mathrm{CO}_{3}$ into the plume thus caused the $\mathrm{KNO}_{3}$ to become supersaturated and form crystals. These crystals were partly taken up in the plume and spread sideways at the top of the fluid layer until their downward velocity exceeded the local root-mean-square turbulent velocity. They then fell from the plume to form a crystal pile at the base encircling the vent. Photographs from an experiment are shown in Figure 6.

\section{Small to Moderate Reynolds Numbers}

In order to examine the form of motion at intermediate Reynolds numbers, we carried out three different series of experiments using water, glycerine, and corn syrup as the working fluids. Values of the density and viscosity of these three fluids are presented in Table 1.

\section{1. $R e_{e}<R e_{i}$ (Smaller Interior Viscosity)}

In the first series of experiments we pumped a water/glycerine mixture at a precalibrated rate through a vent of $7-\mathrm{mm}$ diameter into the base of a denser, initially homogeneous, water/glycerine layer. The layer was nominally $150 \mathrm{~mm}$ deep and was contained in a Perspex box of a $200 \mathrm{~mm} \times 200 \mathrm{~mm}$ cross section. The density and viscosity of the mixtures were determined and checked by the combined use of an hydrometer, a hand-held refractometer, and the tables from Miner and Dalton [1953] and Weast [1971]. The flows were observed visually, using either the standard shadowgraph technique or diffuse lighting from behind, and both still and movie photographs were taken. The values of the input parameters for the 39 experiments and the classification of the flow regimes are shown in Figure 7. For sufficiently small Reynolds numbers, the flow behind the dome at the front was entirely laminar with the input fluid rising in a cylindrical conduit whose radius was determined by the input parameters. This situation is depicted in Figure 8. Note that there was often a large spherical dome ahead of the conduit, as depicted by Whitehead and Luther [1975, Figure 8].

As the Reynolds numbers increased, the flow in the conduit could become unstable. Only two forms of instability were observed. There was either a varicose instability, where the radius of the conduit varies in an axisymmetric fashion with height, as shown in Figure 9, or there was a meander instability, where the axis of the conduit varied with height, as shown in Figure 10. As indicated in Figure 7, the former instability occurred for lower values of $R e_{e}$.

As the Reynolds numbers increased yet further, the perturbation of the flow increased and it was best described as unsteady (Figure 11). With further increase in Reynolds numbers, the flow seemed to be fully turbulent (Figure 12). 


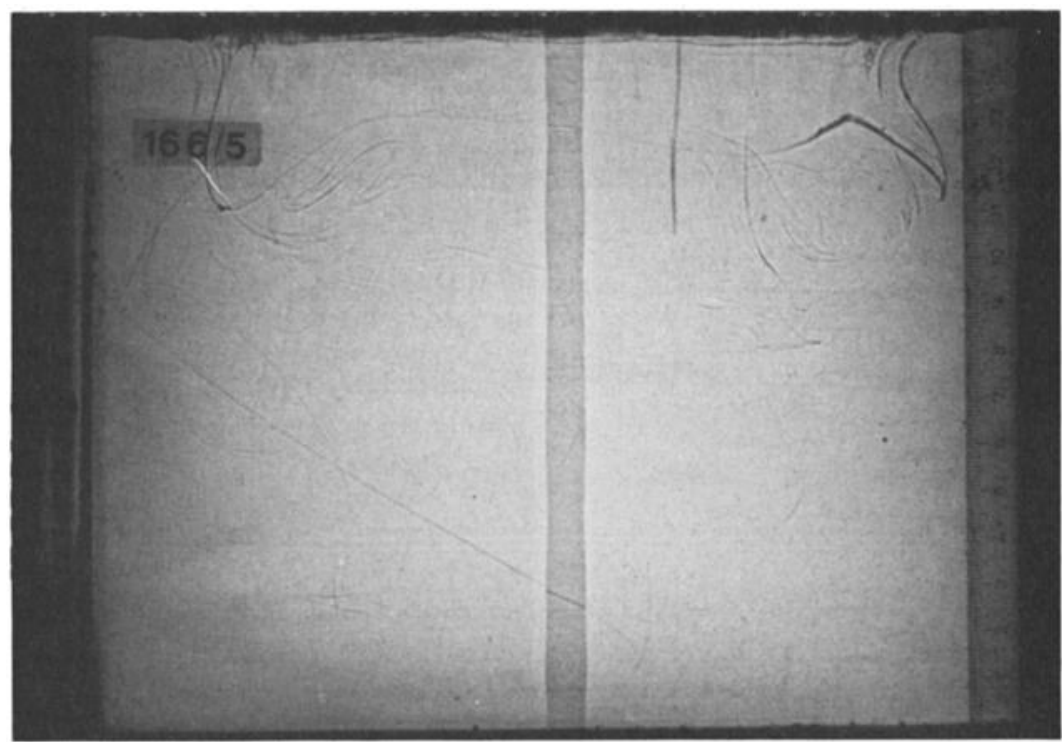

Fig. 8. A photograph of a laminar conduit of a water/glycerine mixture rising through a layer of a water/glycerine mixture of different composition. $Q=1.1 \times 10^{-6} \mathrm{~m}^{3} \mathrm{~s}^{-1}, g^{\prime}=0.12 \mathrm{~m} \mathrm{~s}^{-2}, v_{1}=2.4 \times 10^{-5} \mathrm{~m}^{2} \mathrm{~s}^{-1}, v_{e}=3.8 \times 10^{-5} \mathrm{~m}^{2}$ $\mathrm{s}^{-1}, \operatorname{Re}_{i}=7.3$, and $R e_{e}=4.6$.

In the second series of experiments we introduced pure water at a constant rate to the base of a $254 \times 254 \times 300 \mathrm{~mm}$ deep layer of corn syrup. The water was forced through a 7-mm-diameter hole using the following technique. Three liters of water at $23^{\circ} \mathrm{C}$ was held in a large funnel at a height of either $1.2 \mathrm{~m}$ or $0.45 \mathrm{~m}$ above the free surface of the syrup. The flow rate was controlled by a pinch cock (which connected the funnel to the intrusive hole) and measured by observing the elapsed time necessary to evacuate the $3 \mathrm{~L}$ of water. Another method, useful for the very slow flow rates, was to measure the rate of increase with time of the initially intruding fluid sphere at the beginning of the experiment. Numbers obtained in this way agreed within a few percent with those obtained by measuring the gradually increasing thickness of the water on the top of the syrup.

Before the experiment was commenced, a rod was inserted into the bottom hole to prevent syrup from slowly descending into it and clogging it. An experimental run was started by presetting the governing hose pincher, opening a control valve, and then slowly withdrawing the rod from the hole. For slow rates an L-shaped tube was inserted into the tank and was flushed by an air bubble before the run.

All flows exhibited a varicose instability, as depicted in Figure 7. From Figure 7 it can be seen that the data from this series of experiments, using corn syrup, permitted us to extend the regime diagram to lower values of the external Reynolds number. In addition, we were able to measure the amount of contamination in the following way.

At the end of each experiment, the index of refraction of the water-syrup mixture floating above the syrup was measured. By using calibration data relating the index of refraction to the water content of corn syrup, we were able from the refractive index measurements to determine the final amount of contamination, $\theta$, expressed as the weight percent of corn

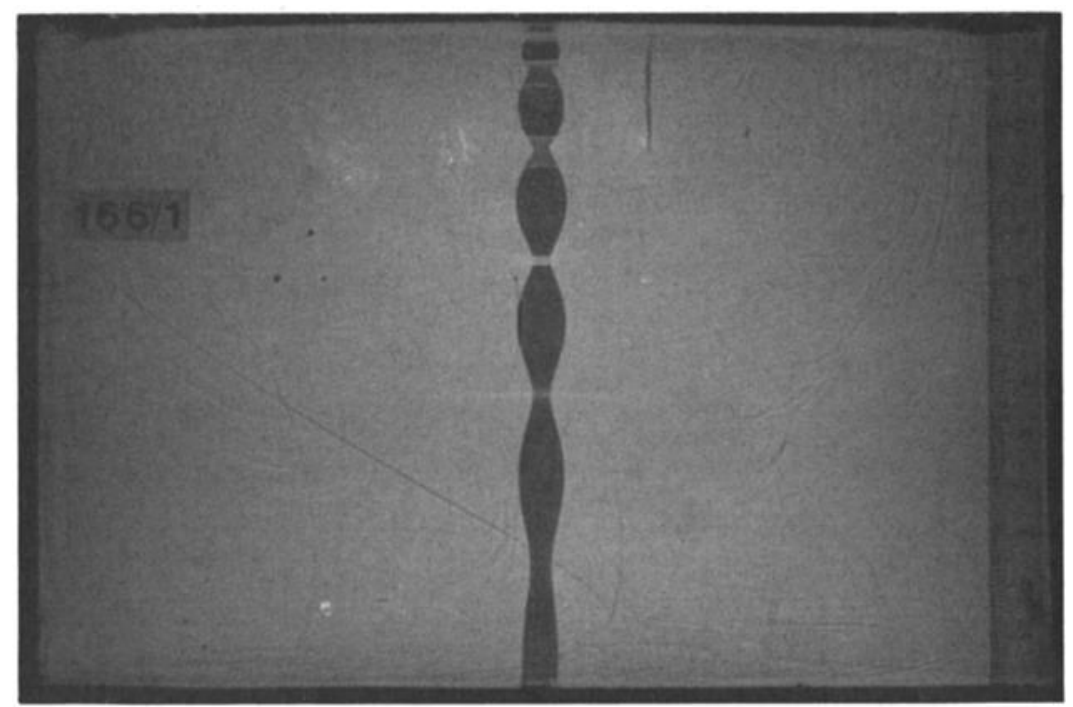

Fig. 9. A photograph of a varicose instability due to a water/glycerine mixture rising through a layer of pure glycerine. $Q=5.2 \times 10^{-7} \mathrm{~m}^{3} \mathrm{~s}^{-1}, g^{\prime}=0.59 \mathrm{~m} \mathrm{~s}^{-2}, v_{i}=2.1 \times 10^{-3} \mathrm{~m}^{2} \mathrm{~s}^{-1}, v_{e}=2.0 \times 10^{-5} \mathrm{~m}^{2} \mathrm{~s}^{-1}, R_{i}=7.3$, and $R e_{e}=7.6$. 


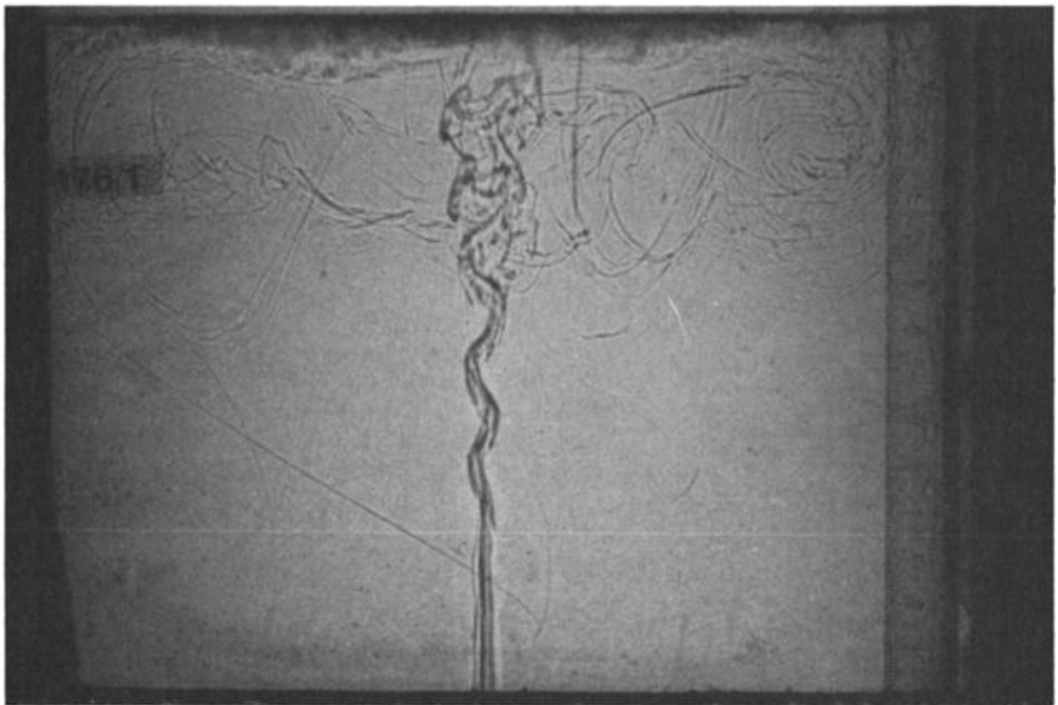

Fig. 10. A photograph of a meander instability due to a water/glycerine mixture rising through a water/glycerine mixture of different composition. $Q=4.4 \times 10^{-7} \mathrm{~m}^{3} \mathrm{~s}^{-1}, g^{\prime}=0.13 \mathrm{~m} \mathrm{~s}^{-2}, v_{l}=2.8 \times 10^{-6} \mathrm{~m}^{2} \mathrm{~s}^{-1}, v_{e}=3.5 \times 10^{-6} \mathrm{~m}^{2}$ $\mathrm{s}^{-1}, R e_{i}=36$, and $R e_{e}=29$.

syrup taken up by the input fluid. We then calculated a mixing coefficient per unit length, $m_{c}$, by dividing $\theta$ by the time taken for the plume to rise to the surface and by the length of the plume. This is a more meaningful determination of the actual effect of mixing, since rapidly vented fluid has proportionally less exposure to the resident fluid than slowly vented fluid.

The values of $m_{c}$ are plotted in Figure 13 as a function of $R e_{i}$. The data increase with increasing $R e_{i}$, which is consistent with the concept that as the internal Reynolds number increases so does the degree of mixing. It is also seen that the data lie quite close to $m_{c} \propto R e_{i}{ }^{7 / 8}$, except possibly for the smaller values of the internal Reynolds number.

It is clear that the experiments do not permit a precise demarcation to be made between the various regimes shown in Figure 7. They were sufficient, however, to give a fair indication of the region of each mode of flow, and we have separated these by drawing simple curves (generally straight lines when $R e_{e}<R e_{i}$ ) in Figure 13.

\section{2. $R e_{i}<R e_{e}$ (Larger Interior Viscosity)}

The easiest way to investigate this regime is to observe relatively dense, viscous fluid falling through a layer of less dense, less viscous fluid. Again we used water/glycerine mixtures which we introduced at the surface of a nominally 200 mm layer contained in the $200 \mathrm{~mm} \times 200 \mathrm{~mm}$ Perspex box already described. The Reynolds numbers of the 35 experiments performed and the classification of the flow regimes are presented in Figure 7.

As in section 3.1, the flow could take the form of a laminar conduit, be unstable to a varicose or meander mode, or be unsteady or turbulent. As before, the dividing lines between the various regimes should be regarded as approximate. What seems reasonable, however, is that the dividing lines between the laminar, meander, unsteady, and turbulent regimes should become vertical as $R e_{e}$ increases, reflecting the fact that in that limit the external fluid plays no role other than to contribute to the buoyancy.

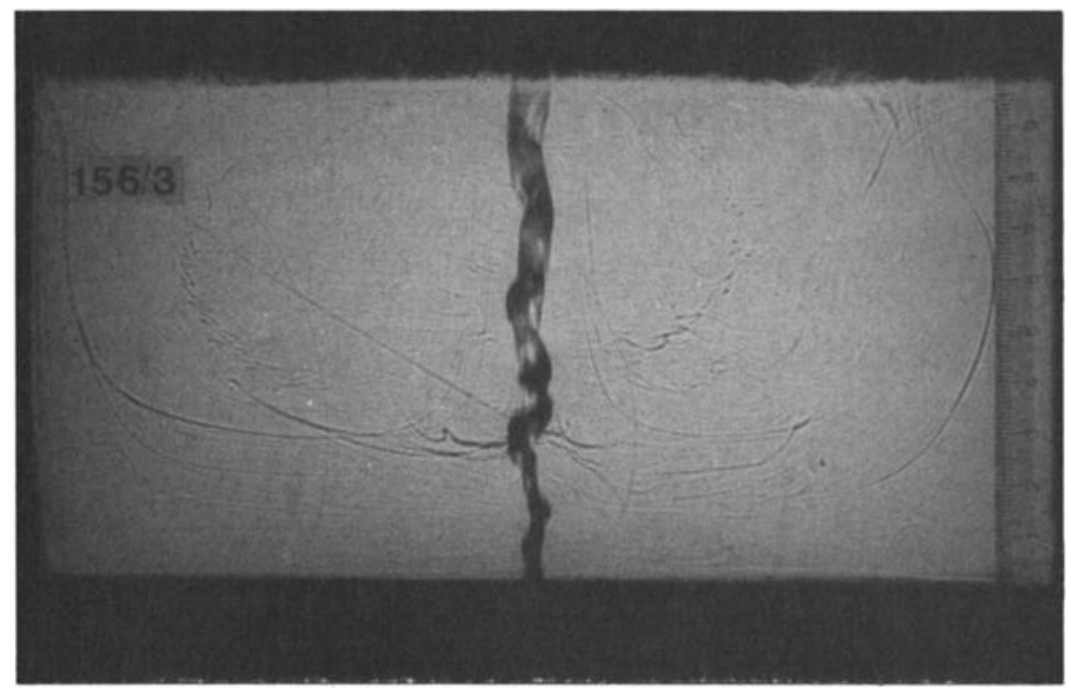

Fig. 11. A photograph of an unsteady plume of water rising through a water/glycerine mixture. $Q=5.3 \times 10^{-7} \mathrm{~m}^{3} \mathrm{~s}^{-1}$, $g^{\prime}=1.62 \mathrm{~m} \mathrm{~s}^{-2}, v_{\mathrm{t}}=1.0 \times 10^{-6} \mathrm{~m}^{2} \mathrm{~s}^{-1}, v_{e}=4.3 \times 10^{-5} \mathrm{~m}^{2} \mathrm{~s}^{-1}, R e_{i}=190$, and $R e_{e}=4.4$ 


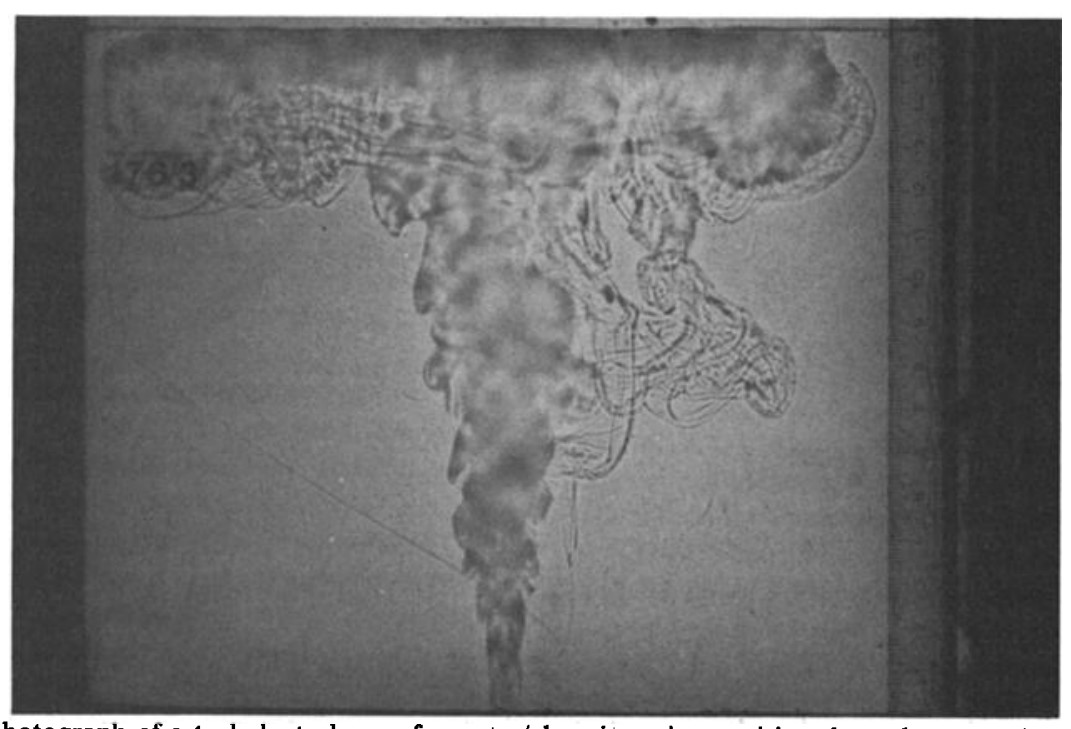

Fig. 12. A photograph of a turbulent plume of a. water/glycerine mixture rising through a water/glycerine mixture of different composition. $Q=1.3 \times 10^{-3} \mathrm{~m}^{3} \mathrm{~s}^{-1}, g^{\prime}=0.13 \mathrm{~m} \mathrm{~s}^{-2}, v_{i}=2.8 \times 10^{-6} . \mathrm{m}^{2} \mathrm{~s}^{-1}, v_{e}=3.5 \times 10^{-6} \mathrm{~m}^{2} \mathrm{~s}^{-1}, R e_{i}=$ 280 , and $R e_{e}=220$.

Note the quite different boundaries of the various flow regimes on either side of the line where the viscosity of plume and resident fluid are equal $\left(R e_{e}=R e_{i}\right)$. This is consistent with the difference in behaviour already documented by Whitehead and Luther [1975] between fluid of one viscosity rising into a less viscous or a more viscous medium.

The exact form of the motion as displayed in Figure 7 should be applied to geological situations with some caution. J. Lister (Cambridge University, unpublished data, 1984) has just completed a calculation of the instability of a rising twodimensional line plume, which indicates that even at low Reynolds numbers the flow may be weakly unstable. Although such an instability was not directly observed in the experiments for low Reynolds numbers, it may be that the instability occurs with a very slow spatial growth rate, which would only be visible after the plume had risen through a considerable height. Thereafter the appropriate Reynolds numbers of the plume would increase with height.

We also note that in all the experiments the resident fluid was static. In a magma chamber the resident fluid is likely to be convecting, and these motions might be strong enough in some situations to disrupt a low Reynolds number laminar plume and to cause mixing of the two fluids.

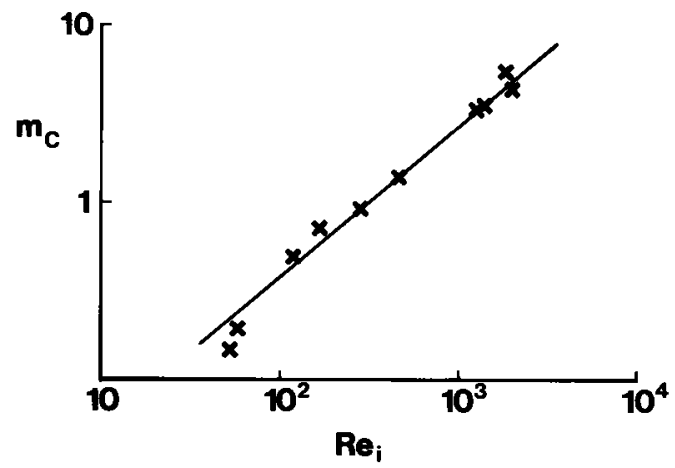

Fig. 13. The mixing coefficient per unit length as a function of the internal Reynolds number for the experiments with water and corn syrup.

\section{GeOlogical ImPlications}

The most important situation in which light inputs can occur is within basaltic magma chambers. They arise because primitive basaltic magmas can often be lower in density than highly differentiated magmas which have fractionated abundant plagioclase [Sparks et al., 1980; Sparks and Huppert, 1984]. Sparks et al. [1980] considered the input conditions to basaltic magma chambers and concluded that Reynolds numbers based on the radius of the vent at the base of the chamber were in the transitional region between about unity and several thousand. Similar values result from using the Reynolds numbers defined by (1). Thus the regimes identified in our Figure 7 could all occur in basaltic systems. In addition, we have shown that the chamber geometry, preexisting compositional stratification, and crystallization can all significantly influence the fluid mechanical behavior. In the following account we reassess the implications of replenishment of a chamber containing differentiated iron-rich tholeiitic basalt by a primitive olivine tholeiite. In such a situation the density difference might be up to a few tens of kilograms per cubic meter, and the viscosity ratio of input to resident magma might vary from almost unity to an excess of 100 .

Provided that the Reynolds numbers exceed a few hundred, intimate mixing of the magmas can be expected. Sparks et al. [1980] thought that a zone of mixed magma would accumulate at the top of the chamber overlying a layer of unaffected differentiated magma. However, the experimental studies reported here suggest that there is a greater diversity of effects, dependent on chamber geometry and the occurrence of preexisting stratification. In chambers and conduits with high aspect ratios and large input Reynolds numbers, mixing can influence most of the chamber, and little stratification would result. Alternatively, in chambers with low aspect ratios, exemplified by sills or sheetlike intrusions such as the Stillwater or Bushveld, the hybrid basaltic magma can be confined to the uppermost parts of the chamber. The layer formed will not be an homogeneous mixture but will be chemically zoned, with the mixed magma layer containing increasing proportions of the new primitive magma towards the top.

Previous discussions of the role of density in preventing 
eruption of primitive magmas from magma chambers have emphasized the high density of the input compared with the resident magma [Huppert and Sparks, 1980]. However, even primitive basaltic magma, input at the density minimum, can be prevented from reaching the surface, either by compositional stratification of the resident magma or by substantial dilution due to mixing in the plume. Preexisting compositional zoning can have a major influence on behaviour. If the basaltic magma chamber is already zoned, the new light primitive magma may be incapable of reaching the top. Unless the stratification is exceedingly weak, it will mix with a sufficient amount of the lower and denser layers in the chamber to spread out as a layer of hybrid magma at some intermediate level in the chamber. This layer will itself be stratified.

Our experiments have also shown that the amount of mixing depends on the relative Reynolds numbers. As input conditions of basaltic magmas span transitional values of Reynolds number, the mixing coefficients for rising plumes can vary greatly (Figure 13). In some cases at low Reynolds number, the new magma may rise to its own density level with very little, if any, mixing. Convection in the resident magma, however, might disrupt some laminar plumes, resulting in mixing of the magmas. In the case of basaltic systems there are several mechanisms for producing zonation within a chamber by light inputs. The diversity of zoning patterns should be reflected in the erupted products and layered-intrusive rocks that form during and after replenishment.

Mixing can lead to rapid crystallization, to changes in the order of crystallization, and sometimes to formation of a superheated melt. The occurrence of each of these effects depends on the topology of the relevant phase diagram as discussed by Irvine [1980]. Since many cotectic surfaces are curved, the effect of mixing is often to produce a hybrid magma within a field of a single phase. For example, mixing of magmas along the olivine-chromite cotectic can lead to precipitation of chromite alone [Irvine, 1977]. Mixing of a primitive magma in the olivine field with a basaltic magma cosaturated in plagioclase-pyroxene and olivine could likewise result in precipitation of olivine alone, even if the primitive magma is strongly diluted. Settling of the crystals formed in such mixing events could lead to unexpected cumulate layers and variations in modal mineralogy within an intrusion. For example, thin layers of olivine cumulate or chromite could form within an otherwise gabbroic sequence as is the case in the uppermost parts of the Rhum layered intrusion [Wager and Brown, 1968]. Campbell et al. [1983] have suggested that the formation of the Merensky Reef of the Bushveld Complex was associated with the ascent of a turbulent plume and the precipitation of sulphide liquid from the hybrid magma. They envisage that the sulphide melt scavenges platinum group elements during mixing and that the sulphide settles over a wide area to form the one body.

The experiments with precipitation of $\mathrm{KNO}_{3}$ suggest the possibility that crystals formed during mixing in a plume may sometimes accumulate preferentially around the vent. A. J. Naldrett (private communication, 1984) suggested to us that this could be an explanation of the chromite pods at the base of the solidified magma chamber in Selukwe, Zimbabwe. The seams are of order $20 \mathrm{~m}$ thick and assay $50 \mathrm{wt} \% \mathrm{Cr}_{2} \mathrm{O}_{3}$ in a chamber of order $1 \mathrm{~km}$ high. This would imply, if the chromite was to lie uniformly at the base of the chamber, a ratio of 1 part per 100 by weight of $\mathrm{Cr}_{2} \mathrm{O}_{3}$. Yet it is believed that the input magma contained at most 1 part per 1000 weight of $\mathrm{Cr}_{2} \mathrm{O}_{3}$, which is an order of magnitude smaller. Naldrett suggested that the chromite may have fallen around the vent, in much the same way as our $\mathrm{KNO}_{3}$, allowing the chromite-free magma to spread sideways. Thus the total ore/magma ratio could be 1 part per 1000 even though the local ratio is much larger.

Irvine [1980] has pointed out that there are 18 possible orders of crystallization in a basaltic system involving the minerals olivine, clinopyroxene, orthopyroxene, and plagioclase. Mixing gives the opportunity of forming hybrid magmas with orders of crystallization which differ from that observed in the primitive magma. Thus a layered intrusion formed by open-system behavior should be characterized by wide variations in modal mineralogy and apparent crystallization sequences. Interpretation of the detailed stratigraphy of layered rocks might include the idea that some layers are the consequence of showers of crystals formed in a plume during replenishment.

Light inputs could also occur in other kinds of magmatic systems. If the pressure is low and the water content of the input magma is sufficiently high, a basaltic magma can become lower in density (due to volatile exsolution) than intermediate or even silicic magma [Eichelberger, 1980; Huppert et al., 1982]. Replenishment in such systems could involve large viscosity ratios and hence large differences in external and internal Reynolds number $\left(\operatorname{Re}_{i} \gg \boldsymbol{R e}_{e}\right)$. Another possibility is if the replenishing magma is rhyolite entering a basaltic chamber, although this situation is not one which is widely invoked. Again, a large difference in Reynolds numbers $\left(R e_{e} \gg R e_{i}\right)$ can occur in such a situation.

We conclude that light inputs are likely to be a widespread phenomenon in magma chambers, especially in those of basaltic composition. This paper provides a general framework of the physical controls in open-system magmatic systems in which light inputs occur. We anticipate that future work will involve detailed assessment of the petrological and geochemical consequences of the various physical processes we have described and application to a wide variety of geological situations.

\section{APPENDIX}

From the four dimensional parameters $Q, g^{\prime}, v_{e}$, and $v_{i}$ describing the input, only two independent, nondimensional parameters can be formed. We have chosen the two expressed in (1), but of course, an infinite number of different choices are possible. The aim of this appendix is to discuss briefly two choices.

Using $X$ and $Y$ to denote the two nondimensional parameters, we have used

$$
\begin{aligned}
& X=\left(g^{\prime} Q^{3}\right)^{1 / 5} / v_{i} \\
& Y=\left(g^{\prime} Q^{3}\right)^{1 / 5} / v_{e}
\end{aligned}
$$

The rationale behind this choice is simply the desire to associate $X$ and $Y$ with internal and external Reynolds numbers which have the internal and external viscosities in the denominator.

Consideration of a laminar conduit of radius $a$ made up of fluid whose viscosity is very much smaller than that of the external fluid [Whitehead and Luther, 1975] indicates that the maximum velocity, say, $W$, at the center of the conduit is given by

$$
W=\frac{1}{4} g^{\prime} a^{2} / v_{\imath}
$$

where

$$
Q=\frac{1}{8} \pi g^{\prime} a^{4} / v_{i}
$$


Thus

$$
W a / v_{i}=\frac{1}{4}(8 / \pi)^{3 / 4}\left(g^{\prime} Q^{3} / v_{i}^{5}\right)^{1 / 4} \propto X^{5 / 4}
$$

while

$$
W a / v_{e}=\frac{1}{4}(8 / \pi)^{3 / 4}\left(g^{\prime} Q^{3} / v_{i}\right)^{1 / 4} / v_{e} \propto X^{1 / 4} Y
$$

Acknowledgments. We are grateful to A. R. McBirney and J. S. Turner for very helpful comments on a earlier draft of this paper. This work has been supported by grants from the BP Venture Research Unit and the NERC. Partial support for J.A.W. and a Symposium on Geological Fluid Mechanics during which some experiments were conducted was received from the Centre for Analysis of Marine Systems of the Woods Hole Oceanographic Institution.

\section{REFERENCES}

Baines, W. D., and J. S. Turner, Turbulent buoyant convection from a source in a confined region, J. Fluid Mech., 37, 51-80, 1969.

Briggs, G. A., Plume rise, critical review series, U.S. At. Energy Commiss., 1969.

Campbell, I. H., A. J. Naldrett, and S. J. Barnes, A model for the origin of the platinum-rich sulfide horizons in the Bushveld and Stillwater complexes, J. Petrol., 24, 133-165, 1983.

Eichelberger, J. C., Vesiculation of mafic magma during replenishment of silicic magma reservoirs, Nature, 288, 446-450, 1980.

Huppert, H. E., and R. S. J. Sparks, The fluid dynamics of a basaltic magma chamber replenished by influx of hot, dense ultrabasic magma, Contrib. Mineral. Petrol., 75, 279-289, 1980.

Huppert, H. E., and R. S. J. Sparks, Double-diffusive convection due to crystallization in magmas, Annu. Rev. Earth Planet. Sci., 12, 11-37, 1984.

Huppert, H. E., and J. S. Turner, A laboratory model of a replenished magma chamber, Earth Planet. Sci. Lett., 54, 144-152, 1981.

Huppert, H. E., R. S. J. Sparks, and J. S. Turner, Effects of volatiles on mixing in calc-alkaline magma systems, Nature, 297, 554-557, 1982.

Irvine, T. N., Origin of chromitite layers in the Muskox intrusion and other strattform intrusions: A new interpretation, Geology, 5, 273$277,1977$.

Irvine, T. N., Rocks whose composition is determined by crystal accumulation and sorting, in The Evolution of the Igneous Rocks, edited by H. S. Yoder, 245-306 pp., Princeton University Press, Princeton, N. J., 1980.

Mellor, J. W., Comprehensive Treatise on Inorganic and Theoretrical Chemistry, 804 pp., Longmans, London, 1965.

Miner, C. S., and N. N. Dalton, Glycerol, Rheinhold, New York, 1953.

Sparks, R. S. J., and H. E. Huppert, Density changes during fractional crystallization of basaltic magmas: Fluid dynamical implications, Contrib. Mineral. Petrol., 85, 300-309, 1984.

Sparks, R. S. J., P. Meyer, and H. Sigurdsson, Density variations amongst mid-ocean ridge basalts: Implications for magma mixing and the scarcity of primitive lavas, Earth. Planet. Sci. Lett., 46, $419-430,1980$.

Sparks, R. S. J., H. E. Huppert, and J. S. Turner, Fluid dynamic behaviour of magma chambers, Philos. Trans. R. Soc. London, Ser. $A, 310,511-534,1984$.

Turner, J. S., Buoyancy Effects in Fluids, Cambridge University Press, New York, 1979.

Turner, J. S., and L. B. Gustafson, The flow of hot saline solutions from vents in the sea floor-Some implications for exhalative massive sulfide and other ore deposits, Econ. Geol., 73, 1082-1100, 1978.

Wager, L. R., and G. M. Brown, Layered Igneous Rocks, Oliver and Boyd, Edinburgh, 1968.

Washburn, E. W. (Ed.), International Critical Tables, McGraw-Hill, New York, 1929.

Weast, R. C. (Ed.), Handbook of Chemistry and Physics, CRC Press, Boca Raton, Fla., 1971.

Whitehead, J. A., and D. S. Luther, Dynamics of laboratory diaper and plume models, J. Geophys. Res., 80, 705-717, 1975.

Worster, M. G., and H. E. Huppert, Time-dependent density profiles in a filling box, J. Fluid Mech., 132, 457-466, 1983.

M. A. Hallworth and H. E. Huppert, Department of Applied Mathematics and Theoretical Physics, University of Cambridge, Silver Street, Cambridge CB3 9EW, England.

R. S. J. Sparks, Department of Earth Sciences, University of Cambridge, Downing Street, Cambridge CB2 3EQ, England.

J. A. Whitehead, Woods Hole Oceanographic Institution, Woods Hole, MA 02543.

(Received December 19, 1984 revised May 3, 1985; accepted June 26, 1985.) 